Article

\title{
Structural Changes of Compacted Soil Layers in Northeast China due to Freezing-Thawing Processes
}

\author{
Li Wang ${ }^{1}{ }^{\mathbb{D}}$, Hengfei Wang ${ }^{1}$, Zhengchao Tian ${ }^{2}$, Yili Lu ${ }^{1}$, Weida Gao ${ }^{1}$ and Tusheng Ren ${ }^{1, * \mathbb{C}}$ \\ 1 College of Land Science and Technology, China Agricultural University, Beijing 100193, China; \\ wangli2015@cau.edu.cn (L.W.); whfei@cau.edu.cn (H.W.); luyili@cau.edu.cn (Y.L.); \\ weida_gao@cau.edu.cn (W.G.) \\ 2 College of Resources and Environment, Huazhong Agricultural University, Wuhan 430070, China; \\ tianzhengchao@mail.hzau.edu.cn \\ * Correspondence: tsren@cau.edu.cn
}

Received: 10 January 2020; Accepted: 18 February 2020; Published: 20 February 2020

\begin{abstract}
Soil compaction has become a global concern that reduces soil quality and may jeopardize agricultural sustainability. The objective of this study is to evaluate if the freezing-thawing process can alleviate the negative effects of soil compaction during overwinter time in Northeast China. The field experiment was a split plot design including two surface treatments (bare and mulch) and three compaction levels (low, moderate, and high compactions with initial bulk densities of 1.2, 1.4 and $1.6 \mathrm{~g} \mathrm{~cm}^{-3}$ ). Results showed that compared with initial values in the fall, freezing-thawing events increased soil porosity (by $4.28 \%$ to $25.68 \%$ ) and the ratio of large-size pores (by $44.5 \%$ to $387.6 \%$ ) after thawing in the spring. The greatest changes were observed in the high compaction treatment, and mulch-enhanced soil structural transformation. Additionally, the ratio of large-size aggregates $(>1 \mathrm{~mm})$ was increased and the fraction of small-size aggregates $(<1 \mathrm{~mm})$ was decreased. These changes in soil structural characteristics were attributed mainly to the modification of ice-filled pores space during the overwinter period. We concluded that the freezing-thawing process was an effective natural force for ameliorating soil compaction in Northeast China.
\end{abstract}

Keywords: freezing and thawing; soil compaction; pore size distribution; aggregate size distribution

\section{Introduction}

Soil compaction is the process of soil densification caused by farm machine traffic, livestock trampling, precipitation and fine particles' sedimentation [1-3]. In agricultural soils, compaction often causes crop yield decline due to reduced aeration, decreased nutrient and water availability, and the restriction of root elongation [4-6]. Soil compaction also induces environmental problems, such as increased runoff [7], soil erosion and water pollution [1,8]. With the development of agricultural mechanization, soil compaction is becoming a widespread detrimental factor of agricultural sustainability [9], especially in countries or regions with rapid development of the national economy.

In cold regions, instead of mechanical disturbance, the freezing-thawing cycle is one of the eco-friendly natural forces that can alleviate the effects of soil compaction by modifying soil structure during overwinter periods [10]. Subsequent changes in soil porosity, pore size distribution and aggregate stability also affect the ability of soils to provide water, gas and nutrients for plant growth [6,11-13]. Unger [14] showed that freezing processes alleviated soil compaction in some years, and the ameliorative effect was more significant in ridged soils than in flat soils. Deng et al. [15] observed a significant increase in plough pan porosity after freezing and thawing, and a close relationship between soil porosity change and daily minimum temperature and initial soil water content. In terms of aggregate size distribution and stability, there are mixed reports in the literature. In laboratory 
studies, Wang et al. [16] and Ma et al. [17] observed that the mean weight diameter of dry aggregate was increased significantly after first few cycles, but was decreased with additional freezing and thawing processes, and the results were also affected by initial soil water content. Alternatively, there are doubts about the usefulness of freezing and thawing on improving soil physical properties $[18,19]$.

A key reason for the above controversy comes from the fact that the effectiveness of freezing-thawing cycles on soil's physical properties depends on soil texture, exchangeable sodium percent level, initial water content, bulk density, soil plasticity, freezing and thawing history, and the number of freeze-thaw cycles [20-23]. In addition, there is a general lack of understanding about the thermal and hydraulic processes associated with the changes in soil structure. For example, in theory, soil expansion/shrinkage caused by ice formation and melting should be responsible for the changes in soil porosity and pore size distribution during overwinter time. In practice, the dynamics of ice content are seldom measured during freezing and thawing. As a result, little information is available about change of soil pore size distribution before and after freezing [24].

Since 1980s, the numbers of small four-wheel tractors and medium power tractors in China have been increased from 2.0 to 13.2 million, and from 0.79 to 0.83 million, respectively [25]. These vehicles are producing severe soil compaction problems, which pose risks in agricultural production, especially in the black soil region (covers parts of Heilongjiang, Jilin, and Liaoning provinces) of Northeast China [25]. At present, subsoiling is encouraged by local agricultural authorities to alleviate soil compaction $[25,26]$. This practice, however, is unsustainable because it is expensive, energy and labor intensive, and likely to produce secondary compaction if the operation is conducted at soil water contents out of the optimum range [1,5]. In contrast, little attention has been paid to the remediation of compacted layers by natural processes such as the freezing and thawing cycle, which could increase soil porosity and hydraulic conductivity in this region [17].

The objective of this study is to investigate the effects of freezing-thawing on the structure of compacted soil layers, as indicated by soil porosity, pore size distribution, and aggregate size distribution during the overwinter period. Our hypothesis is that during the long and cold winter period in Northeast China, changes in soil hydraulic processes due to water redistribution and ice formation modify soil porosity and pore size distribution significantly, which also alter soil aggregate size distribution and stability.

\section{Material and Methods}

\subsection{Site and Experimental Design}

The experiment was conducted at the Lishu Experimental Station of China Agricultural University (latitude $43^{\circ} 16^{\prime} \mathrm{N}$, longitude $124^{\circ} 26^{\prime} \mathrm{E}$, altitude $194 \mathrm{~m}$ ), which is located in Lishu county of Jilin Province, China. According to the World Reference Base for Soil Resources, the soil is Phaeozems, which has a silt clay loam texture ( $15.9 \%$ sand, $46.8 \%$ silt, and $37.3 \%$ clay), a mean organic matter content of $17.7 \mathrm{~g} \mathrm{~kg}^{-1}$ and a cation exchange capacity of $25.3 \mathrm{cmol}_{\mathrm{c}} \mathrm{kg}^{-1}$ in the 0 to $40 \mathrm{~m}$ layer. The long-term mean annual air temperature is $5.9^{\circ} \mathrm{C}$, with a maximum temperature of $29.7^{\circ} \mathrm{C}$ in July and a minimum temperature of $31.8^{\circ} \mathrm{C}$ in January. The mean annual precipitation and snow cover depth are approximately 472.8 and $22.4 \mathrm{~mm}$, respectively. Figure 1 presents the daily mean air temperature and precipitation during the study periods from 2016 to 2018.

The experiment was established as a split plot design in the overwinter periods of 2016/17 and 2017/18. The main treatment was surface residue cover: After maize harvest, soil surface was kept either bare or covered with maize residue (snow cover remained the same for both). The sub-treatment had three compaction levels, as denoted by three bulk densities: $1.2,1.4$, and $1.6 \mathrm{~g} \mathrm{~cm}^{-3}$, which were used to represent the normal, moderate, and high densities of the soil under study. According to local reports, maize root growth was negatively affected at a bulk density of $1.4 \mathrm{~g} \mathrm{~cm}^{-3}$, and was severely restricted at a bulk density of $1.6 \mathrm{~g} \mathrm{~cm}^{-3}$. Farmers are encouraged to practice subsoiling to eliminate the adverse effects of soil compaction. 

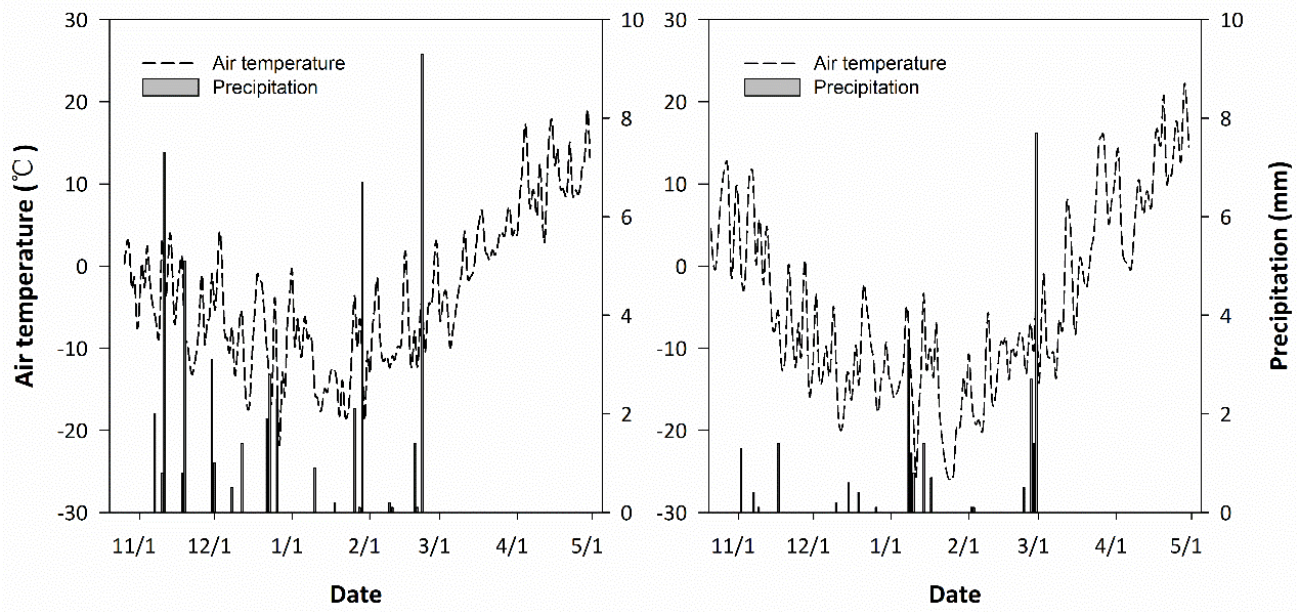

Figure 1. Daily mean air temperature and precipitation during the 2016/2017 (left) and 2017/2018 (right) overwinter periods.

We manually prepared $10 \mathrm{~cm}$ compacted soil layers to simulate the three compaction levels. The study site was divided into two plots; each had an area about $18 \mathrm{~m}^{2}$. First, the top $(0$ to $15 \mathrm{~cm})$ soil layer was segregated into small blocks, moved out of the field with natural structure maintained, and wrapped with plastic film to avoid soil moisture loss. Then, the soil (with a water content of $0.17 \mathrm{~g} \mathrm{~g}^{-1}$ ) from the 15 to $25 \mathrm{~cm}$ layer was excavated, mixed thoroughly (during which roots and other visible impurities were removed), passed through an $8 \mathrm{~mm}$ sieve, and packed into PVC cylinders (height of $10 \mathrm{~cm}$ and inner diameter of $30 \mathrm{~cm}$ ) with preset bulk densities of $1.2,1.4$ and $1.6 \mathrm{~g} \mathrm{~cm}^{-3}$. Next, the soil cylinders were placed back to the excavated sites (i.e., in the 15 to $25 \mathrm{~cm}$ layer), and the intact blocks of the top layer $(0$ to $15 \mathrm{~cm})$ were brought back and put on top of the packed soil columns. The gaps between the soil blocks were filled with fine-grain soil. The compaction treatments were repeated three times. Finally, one plot was covered with corn stalks (hereafter mulch) at a rate of $1.38 \mathrm{~kg} \mathrm{~m}^{-2}$, and the other plot was kept free of crop residual (hereafter bare) (Figure 2).

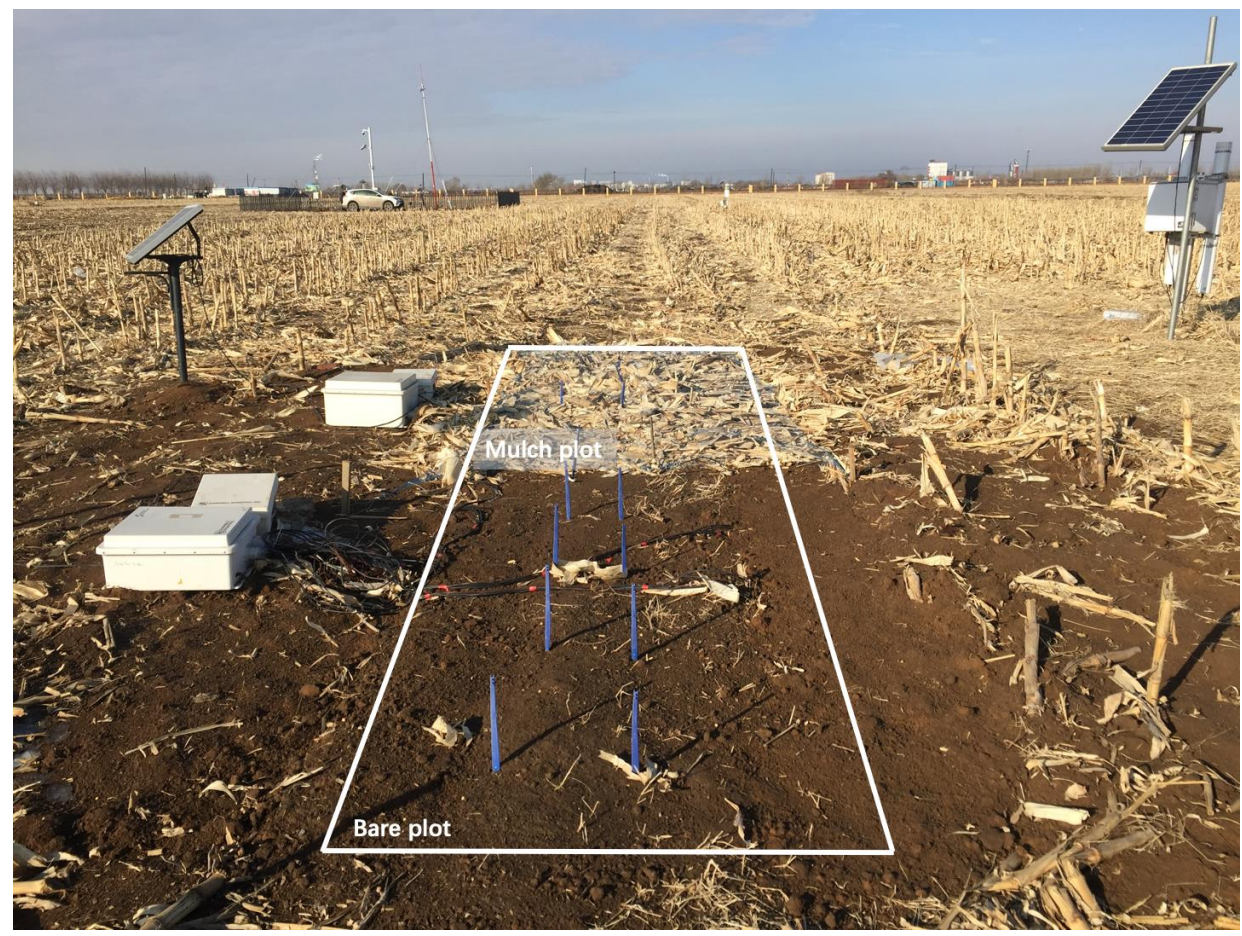

Figure 2. Field setup of the study in fall of 2016. 
The field study was repeated in the 2017/2018 winter season. The treatments and experimental procedures were kept the same, except that the initial soil water content of the compacted layers was about $0.14 \mathrm{~g} \mathrm{~g}^{-1}$, which was lower than that of the 2016/2017 season.

\subsection{Field Measurements}

We monitored the dynamics of soil temperature and liquid (unfrozen) water content during the freezing-thawing periods of the 2016/2017 and 2017/2018 winter seasons. For soil temperature measurements, E-type thermocouples were installed at 5, 10, 20 and $40 \mathrm{~cm}$ depths, and soil temperatures were recorded at a $30 \mathrm{~min}$ interval with a datalogger (Model CR3000, Campbell Scientific, Logan UT, USA). For liquid water content measurement, 3-rod TDR sensors ( $75 \mathrm{~mm}$ long, $2 \mathrm{~mm}$ rod diameter, and $15 \mathrm{~mm}$ rod-to-rod spacing) were installed horizontally at 5, 10, 20 and $40 \mathrm{~cm}$ depths, and liquid water contents were measured with a TDR 100 system (Campbell Scientific, Logan UT, USA), which was controlled with the CR3000 datalogger. Soil temperature and liquid water content measurements were initiated on 26 October 2016 and 23 October 2017, respectively, and terminated on 2 April 2017 and 8 April 2018, respectively.

Additionally, we measured the total water (i.e., liquid water plus ice) content in the 0 to $80 \mathrm{~cm}$ layer at a $20 \mathrm{~cm}$ increment biweekly in the 2017/2018 season. For each compaction treatment, aluminum access tubes were installed in a pre-drilled hole at the center location of the soil column. Total water content was measured with a neutron probe meter (Model 503DR1.5, Instrotek, Campbell Pacific Nuclear International, Concord, CA) by recording hydrogen counts in air (i.e., standard count, $H_{\text {std }}$ ) and at a designated depth $\left(H_{\mathrm{c}}\right)$. The total volumetric soil water content $\left(\theta_{\text {tot }}\right)$ was calculated with Equation (1),

$$
\theta_{\text {tot }}=0.3134 * \frac{H_{c}}{H_{s t d}}-0.1813
$$

The ice content $\left(\theta_{\mathrm{i}}\right)$ of the soil column was estimated from the difference between total soil water content and liquid water content, assuming that hydrogen contribution from soil organic matter could be ignored,

$$
\theta_{i}=\theta_{\text {tot }}-\theta_{w}
$$

The fraction of ice-filled pores $\left(f_{i}, \%\right)$ was calculated with following equation,

$$
f_{i}=\frac{\theta_{i}}{p_{t o t}-\theta_{w}} \times 100 \%
$$

where $p_{\text {tot }}$ is the initial total porosity $\left(\mathrm{cm}^{3} \mathrm{~cm}^{-3}\right)$ of compacted soil in the fall.

\subsection{Laboratory Measurements}

Intact soil cores were collected in the fall and spring to determine bulk density changes in the compacted layers during the freezing and thawing processes. The ring sampler had a volume of $100 \mathrm{~cm}^{3}$ ( $5 \mathrm{~cm}$ ID and $5 \mathrm{~cm}$ in height). In both years, six samples were collected from two extra columns (which were prepared the same way as discussed earlier) in the fall and three samples were collected from each column in the spring. The samples were oven-dried at $105{ }^{\circ} \mathrm{C}$ for $24 \mathrm{~h}$ to determine the weight of soil solids. Finally, soil bulk density was obtained, and total porosity was estimated from the bulk density data.

Meanwhile, disturbed soil samples were collected for analyzing the fractions of dry aggregate distribution changes before and after winter. Soil samples (about $1 \mathrm{~kg}$ each) were obtained in the excavated layer before packing and from the cylinders at the end of thawing. Larger clods were gently broken into particles less $8 \mathrm{~mm}$, passed through a nest of sieves with 2, 1, 0.5 and $0.25 \mathrm{~mm}$ meshes by shaving manually for $30 \mathrm{~s}$. The remaining particles on each sieve and those passed through the 
$0.25 \mathrm{~mm}$ sieve were collected, oven-dried, and weighted. The fraction of a specific aggregates size $\left(f_{a}\right.$, $\%)$ was calculated from,

$$
f_{a}=\frac{m_{s}}{m_{t}} \times 100 \%
$$

where $m_{\mathrm{s}}$ is the weight of soil that remains on the sieve for a given size, $m_{\mathrm{t}}$ is the total weight of soil before sieving. For a specific treatment, the change of an aggregate fraction was obtained from the difference of measured $f_{\mathrm{a}}$ values before and after winter.

Soil water retention measurements were conducted with intact soil cores (with an ID of $5 \mathrm{~cm}$ and a height of $1 \mathrm{~cm}$ ) collected on packed soil columns in the fall and spring. A Sandbox device (Eijkelkamp Soil \& Water, the Netherlands) was used to measure soil water contents at matric suctions of 5, 10, 20, 40, 60, 80 and $100 \mathrm{~cm}$. A pressure chamber apparatus was used to determine soil water desorption characteristics in the matric suction range from 100 to $15,000 \mathrm{~cm}$.

We employed the van Genuchten [27] function to describe the soil water retention curves,

$$
\begin{gathered}
\theta_{(h)}=\theta_{r}+\frac{\theta_{s}-\theta_{r}}{\left[1+\left(\alpha|h|^{n}\right)\right]^{m}} \\
m=1-\frac{1}{n}
\end{gathered}
$$

where $h$ is the matric suction in $\mathrm{cm}, \theta_{(\mathrm{h})}\left(\mathrm{cm}^{3} \mathrm{~cm}^{-3}\right)$ is the water content at matric suction of $h, \theta_{\mathrm{r}}$ $\left(\mathrm{cm}^{3} \mathrm{~cm}^{-3}\right)$ is the residual water content at matric suction of $15,000 \mathrm{~cm}, \theta_{\mathrm{s}}\left(\mathrm{cm}^{3} \mathrm{~cm}^{-3}\right)$ is the saturated soil water content, and $\alpha, m, n$ are empirical constants. In our study, $\alpha, m, \theta_{r}$, and $\theta_{\mathrm{s}}$ were estimated by fitting Equations. (5) and (6) to the measured data. The nonlinear optimization and parameter estimation were accomplished with Solver in Microsoft Excel.

Finally, the pore size distribution of the compacted layers before and after winter were calculated by using the Reynolds et al. [28] model, which describes the changes in the $S$-value (i.e., the magnitude of the slope of the soil water release or desorption curve at the inflection point, introduced by Dexter [29]) by using parameters of the van Genuchten water retention function,

$$
\mathrm{S}(h)=-m n\left(\theta_{s}-\theta_{r}\right) \alpha^{n} h^{n}\left[1+(\alpha h)^{n}\right]^{-(m+1)}
$$

\subsection{Statistical Analysis}

We applied the one-way ANOVA-LSD procedure of SPSS (version 22) software to determine treatment effects on soil porosity before and after winter at the significance level $(P)$ of 0.05 .

\section{Results}

\subsection{Overwinter Changes in Soil Porosity of the Compacted Layer}

Initial soil porosity of the compacted layers fell in the range of 0.38 to 0.53 in fall of 2016 (Figure 3). The corresponding values in spring of 2017 ranged from 0.44 to 0.56 under bare treatment, and from 0.49 to 0.55 under mulch treatment, indicating an overwinter increase in soil porosity. The magnitude of porosity change, however, differed considerably among the three levels of compaction: the least change (0.02-0.03) appeared in the low compaction treatment, while the greatest change $(0.05-0.10)$ occurred in the high compaction treatment.

Comparing to that of the bare surface plot, greater soil porosity changes were observed in the mulch plot (Figure 3). For example, in the 2016/2017 season, the total porosities of the low, moderate, and high compaction levels of the bare plot were increased by $6.18 \%, 11.79 \%(P<0.01)$ and $12.80 \%$ $(P<0.01)$, respectively; the corresponding changes were $4.28 \%(P<0.01), 15.20 \%(P<0.01)$ and $25.68 \%$ $(P<0.01)$ in the mulch plot. 
A soil porosity increase due to compaction was also observed in the 2017/2018 overwinter season (Figure 3). However, the extents of porosity changes in 2017/2018 were generally lower than in 2016/2017.

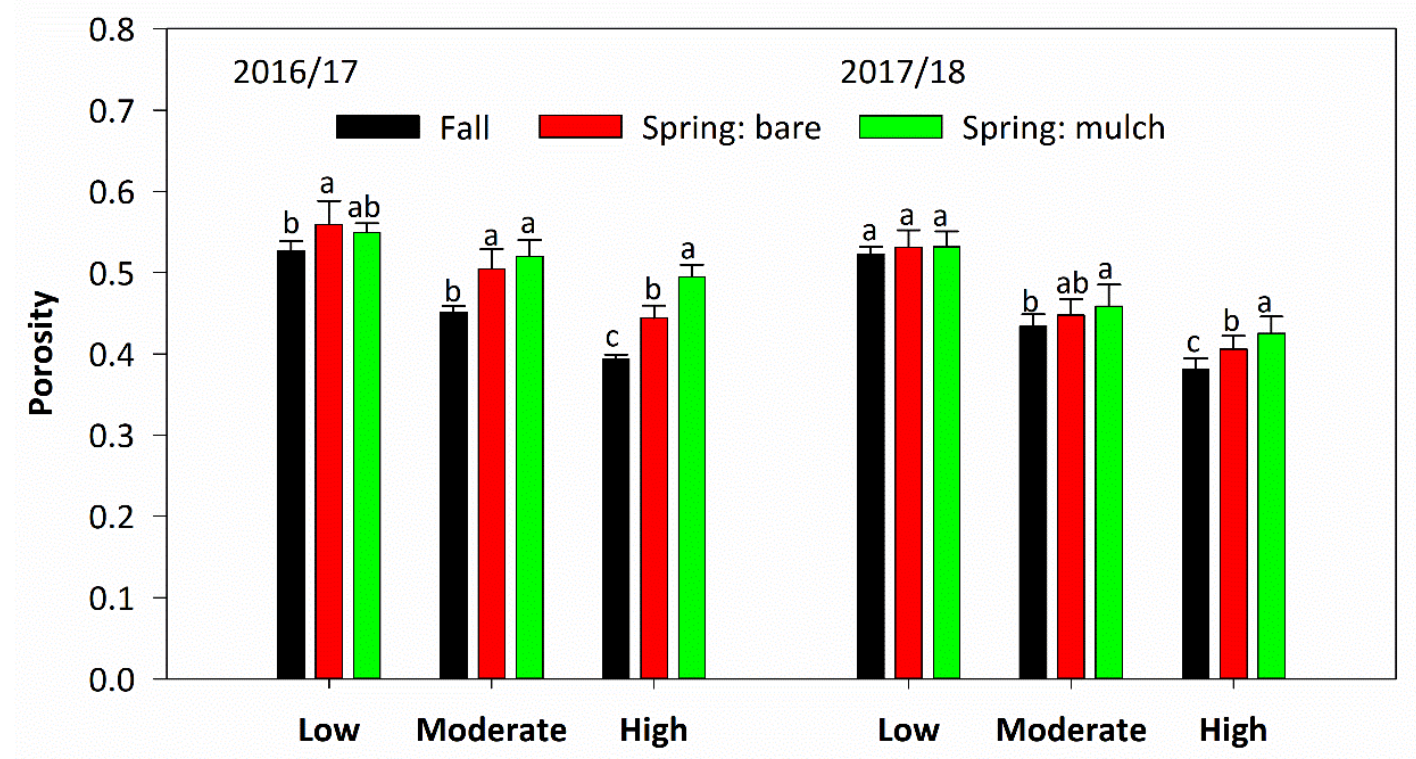

Figure 3. Overwinter changes in total porosity of the three compacted layers in the 2016/2017 and 2017/2018 seasons. Different lowercases indicate that total porosity values between spring and fall (within the same compaction level) differ significantly at $P<0.05$. Low, moderate and high represent three soil compaction levels with an initial bulk density of $1.2,1.4$, and $1.6 \mathrm{~g} \mathrm{~cm}^{-3}$, respectively.

\subsection{Overwinter Changes in Soil Pore Size Distribution}

Soil pore size distributions of the compacted layers before and after winter were estimated with the Reynolds et al. [28] model (Equation (7)) by using water retention data of intact soil cores (Figure 4). The initial (i.e., before freezing) pore size distribution differed considerably among the three compaction levels: the greater in degree of soil compaction, the less large pores, the smaller the median pore diameter (153.1, 36.0, and $7.2 \mu \mathrm{m}$ for the low, moderate, and high compaction levels, respectively), the lower the pore volume density peak $(0.040,0.035$ and 0.026 for the low, moderate, and high compaction levels, respectively). Following Deeks et al. [30], we set $50 \mu \mathrm{m}$ as the boundary between large pores and small pores. Then, the cumulative volume densities of large pores were approximately 2.008, 0.875 and 0.315 for the low, moderate, and high compaction levels, respectively.

Soil pore size distribution was modified significantly during the overwinter period, as indicated by the higher portions of larger pores and greater median pore diameters under all three levels of compaction at the end of thawing (Figure 4). However, these changes were most apparent in the high compaction level, and least in the low compaction level. Under bare soil surface, for example, comparing with the initial values, the large pores in the spring 2017 were increased by $44.5 \%, 78.6 \%$ and $135.9 \%$ for the low, moderate, and high compaction levels, respectively. The corresponding values under mulch treatment were $47.6 \%, 113.3 \%$ and $387.6 \%$, respectively. In terms of the median pore diameter, it became 850.3, 122.4 and $26.6 \mu \mathrm{mm}$ in the bare plot under the low, moderate, and high compaction levels, respectively, and the corresponding values in the mulch plot were 711.9, 102.0 and $122.4 \mu \mathrm{m}$, respectively. 

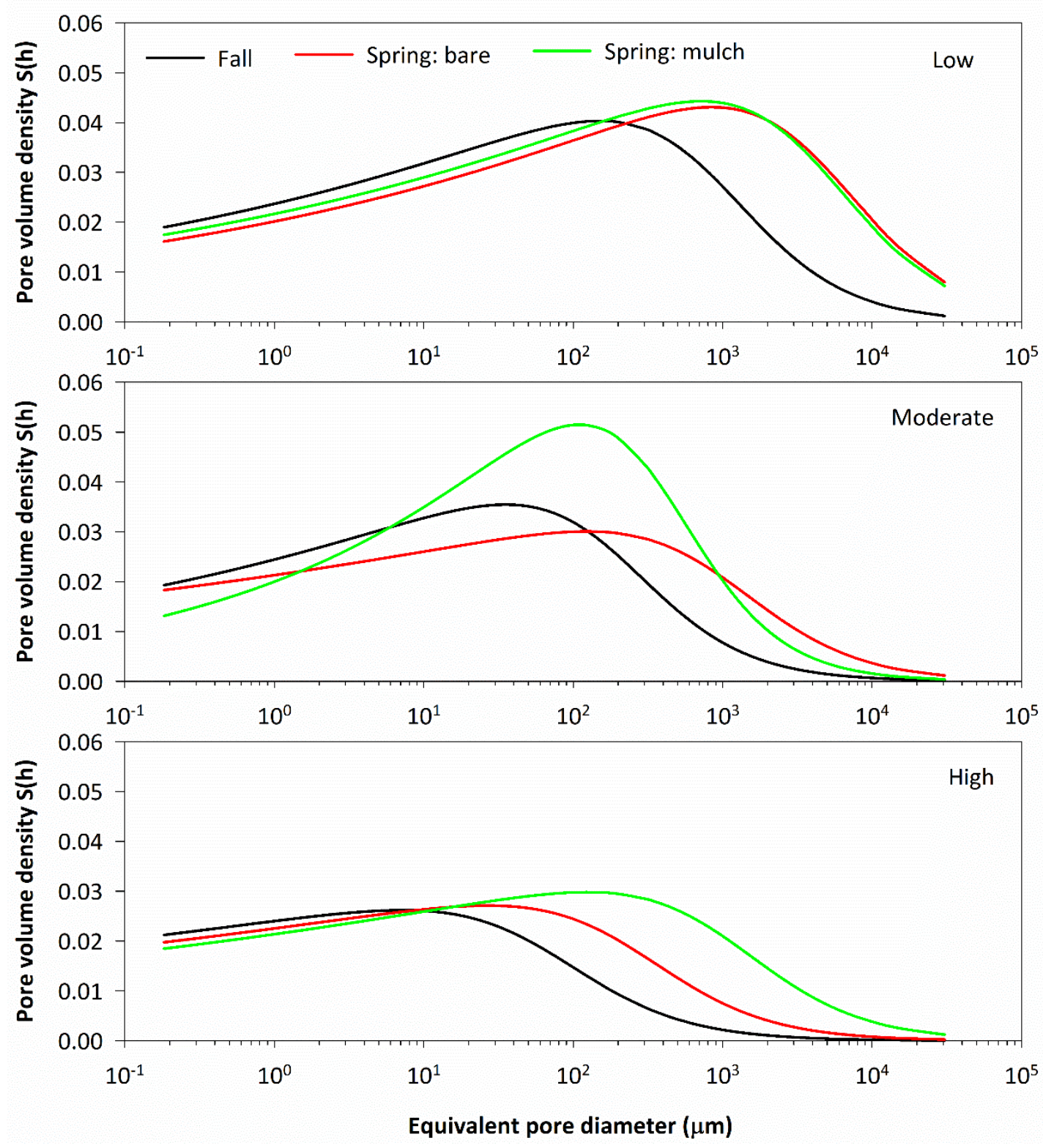

Figure 4. Overwinter changes in pore size distribution of the compacted layer under three compaction levels with bare and mulch treatments in the winter of the 2016/2017 season. Low, moderate and high represent three soil compaction levels with an initial bulk density of $1.2,1.4$, and $1.6 \mathrm{~g} \mathrm{~cm}^{-3}$, respectively.

\subsection{Overwinter Changes of Dry-sieved Aggregate-size Distribution}

Figure 5 presents the changes of dry-sieved aggregate-size distribution of compacted layers before and after winter under mulch and bare treatments. Except for a few cases, the proportions of larger aggregates $(>1 \mathrm{~mm})$ were increased while the proportions of smaller aggregates $(<1 \mathrm{~mm})$ were decreased during the overwinter period. For the low, moderate, and high compaction levels, the larger aggregates were increased by $8.67 \%, 1.20 \%$ and $2.40 \%$ respectively, in the 2016/2017 season; the corresponding changes were $7.84 \%, 3.58 \%$, and $6.77 \%$, respectively, in the $2017 / 2018$ season. Conversely, the aggregates smaller than $1 \mathrm{~mm}$ were decreased by the same proportions. Among the three compaction levels, greater changes in aggregate-size distribution appeared in the low and high compaction treatments, while the least response was observed under moderate compaction (Figure 5). 


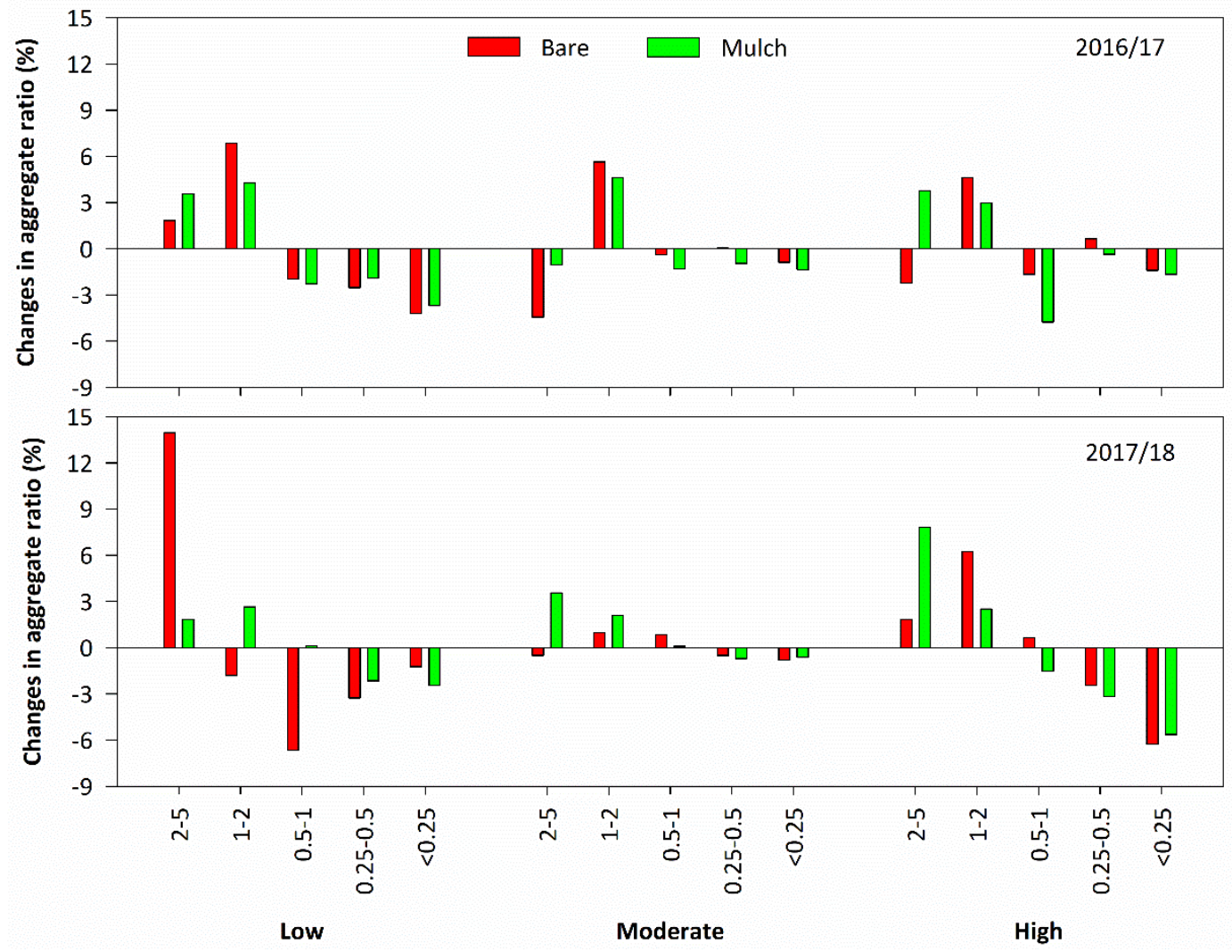

Figure 5. Overwinter changes in aggregate-size fraction at different compaction levels under mulch and bare treatments in the 2016/2017 and 2017/2018 seasons. Low, moderate and high represent three soil compaction levels with an initial bulk density of $1.2,1.4$, and $1.6 \mathrm{~g} \mathrm{~cm}^{-3}$, respectively.

\section{Discussion}

\subsection{Overwinter Changes in Soil Porosity and Pore Size Distribution}

During the overwinter periods of the 2016/2017 and 2017/2018 seasons, we observed significant increases in soil total porosity (from $4.28 \%$ to $25.68 \%$ ), volume of large pores (from $44.5 \%$ to $387.6 \%$ ), and median pore diameter $(>183.3 \%)$ and the extent of changes were enhanced with increasing compaction level. These results are similar to many previous reports that freeze-thaw cycles decrease soil bulk density, and increase soil porosity or permeability [15,17,24,31]. For example, Zhang and Cui [24] compared the pore size distribution before and after freezing-thawing on a silty clay soil by using the technique of mercury intrusion. An increase in the volumetric fraction of large pores and a decrease in the fraction of small pores were observed.

For an initially loose soil, the porosity may decrease after freezing and thawing [21,32]. There are reports that freezing-thawing cycles have bidirectional effects on soil porosity: if soil porosity is greater than the porosity corresponding to a "normal" bulk density, which is a function of percentage of clay and silt for a specific soil [20], soil porosity will decrease [31], and vice versa. Following Heinonen [20], we obtained a theoretical "normal" bulk density of $1.46 \mathrm{~g} \mathrm{~cm}^{-3}$ for the soil under study, which was greater than the bulk density $\left(1.25 \mathrm{~g} \mathrm{~cm}^{-3}\right)$ of our low compaction level, suggesting that the function proposed by Heinonen [20] was not applicable to the silt clay loam soil of our study site. Other factors, e.g., soil organic matter content, initial water content, and freezing-thawing temperature, may also affect the value of "normal" bulk density.

The increase in soil total porosity and fraction of large pores during freezing-thawing cycles or overwinter periods is generally explained by the volume-expansion theory, which states that the formation of ice causes the expansion of soil pores, especially those large size ones $[17,33,34]$. 
A segregation ice model has been proposed to describe soil porosity changes due to ice growth with migration of water to freezing centers [35]. However, few studies have examined the relationship between ice content and change in porosity quantitatively. Our measurements in the 2017/2018 season showed that the three compaction levels had similar ice contents, with a maximum value of about $0.10 \mathrm{~m}^{3} \mathrm{~m}^{-3}$ at the relatively stable periods (Figure 6). Thus, the differences in total porosity and pore size distribution among the three compaction levels could not be explained by ice content. In contrast, the fraction of ice-filled pores, which was calculated with Equation (3), increased significantly with compaction levels from 15 December 2017 to 15 February 2018 (Figure 7). For the low, moderate, and high compaction levels, the peak values of iced-filled pore fractions under bare treatment were $27.9 \%$, $31.0 \%$ and $50.7 \%$, respectively, and the corresponding values under mulch treatment were $32.4 \%, 36 \%$ and $47.0 \%$, respectively. Clearly, ice-filled porosity increased proportionally with compaction level. Comparing with the low compaction treatment, there was a higher contact stress between ice and soil particles under the high compaction treatment, which caused a greater "disjointing pressure" that acted on the interface, pushing soil particles apart at a greater distance [34], which led to the largest overwinter change in soil porosity. These analyses also suggest that the fraction of ice-filled pores is an effective indicator of soil pore characteristics under frozen conditions.

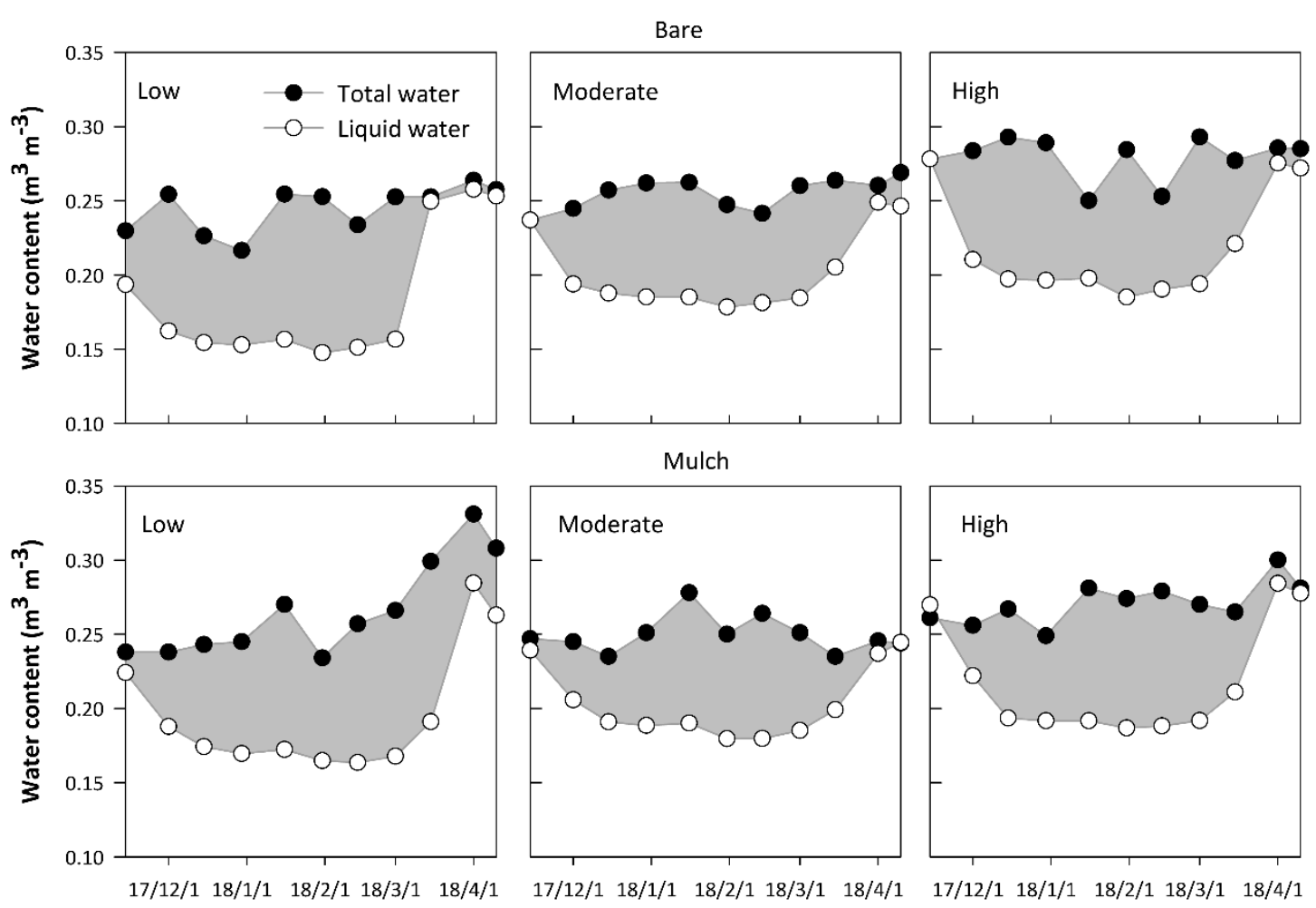

Figure 6. Dynamics of ice content in the compacted soil layers under bare and mulch treatments measured at a biweekly interval in the 2017/2018 season. Shade parts represent the ice contents that are obtained by the differences between total water content and liquid water content. Low, moderate and high represent three soil compaction levels with an initial bulk density of 1.2, 1.4, and $1.6 \mathrm{~g} \mathrm{~cm}^{-3}$, respectively.

At the same compaction level, a greater change in soil porosity was observed in 2016/2017 than that in 2017/2018 under both bare and mulch treatments. This could be explained mainly by the differences in initial soil water contents. During freezing-thawing or wetting-drying processes, high water contents usually have stronger effects on soil physical properties than low water contents [36,37]. Under bare treatment, the initial water contents of low, moderate, and high compaction treatments in the 2016/2017 season were $0.27,0.38$ and $0.43 \mathrm{~cm}^{3} \mathrm{~cm}^{-3}$, respectively, and those in the 2017/2018 season 
were $0.19,0.24$ and $0.28 \mathrm{~cm}^{3} \mathrm{~cm}^{-3}$, respectively. Similar trends also existed under the residues' mulch treatments in both years. At a given compaction level, soils with high initial water content will form more ice, accompanying about a $9 \%$ expansion in the volume, which will push open a larger pore [38]. At a low initial water content, ice crystal only occurs in soil pores, and there is hardly any expanding force [39].

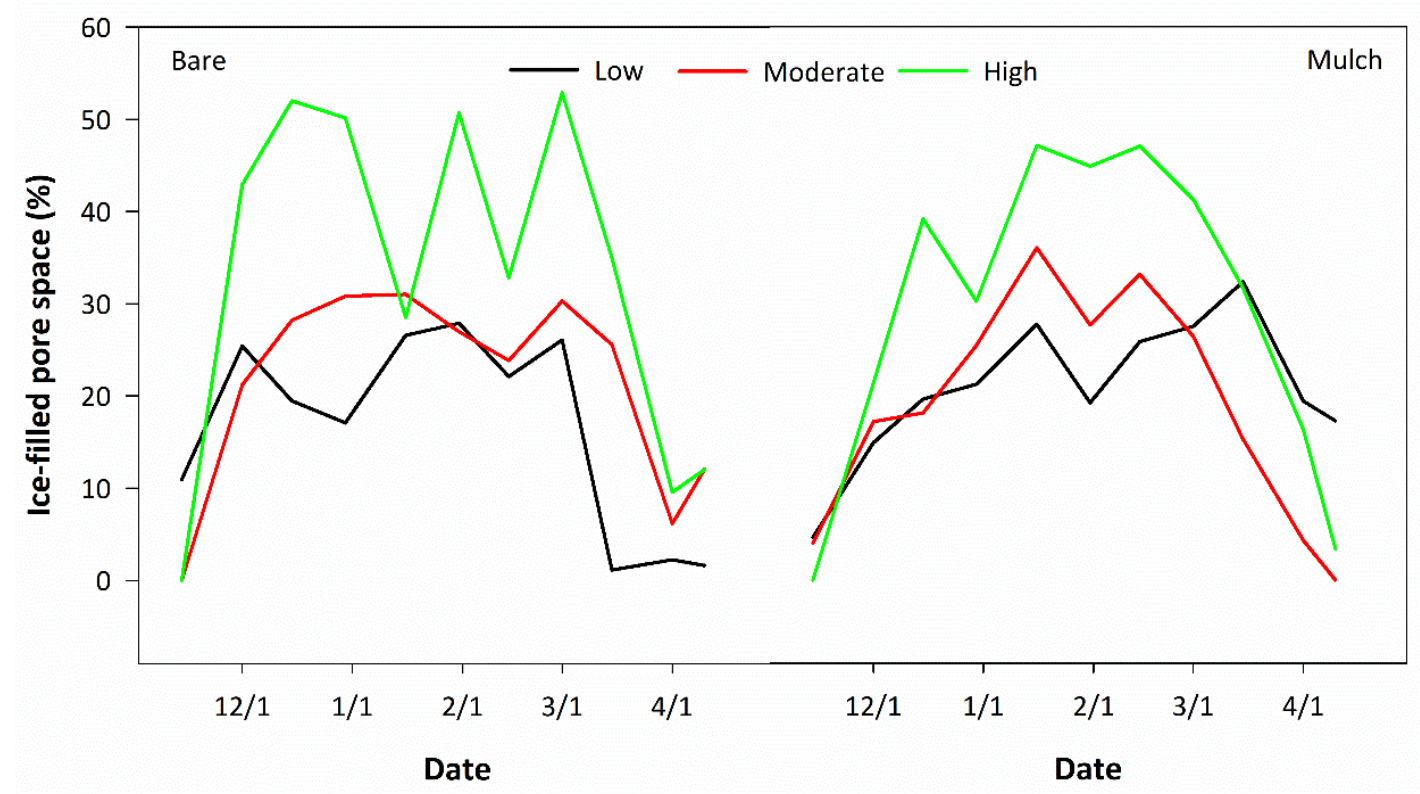

Figure 7. Dynamic of the proportion of ice-filled pores in the three compaction layers under bare and residue mulch treatments. Measurements were made in the winter of 2017/2018. Ice-filled pore space was calculated with Equation (3). Low, moderate and high represent three soil compaction levels with an initial bulk density of $1.2,1.4$, and $1.6 \mathrm{~g} \mathrm{~cm}^{-3}$, respectively.

Many studies suggest that the amelioration effects of freezing-thawing cycles on soil structure depend on the magnitude of temperature variation and the number of freezing-thawing cycles (e.g., Oztas and Fayetorbay [22]). In our study, the three compaction levels experienced the same number of freezing-thawing cycles. Although the mulch treatment reduced the magnitude of temperature variation compared with that of the bare treatment (data not shown), the mulch treatment had larger overwinter changes in soil porosity, indicating that the magnitude of temperature variation and number of freezing-thawing cycles were not the key factors altering soil structure. It was initial soil water content that determined the alleviating effects of freezing-thawing on soil compaction in Northeast China.

\subsection{Aggregate-size Distribution as Affected by Freezing and Thawing Processes}

Our study indicated that the ratio of large aggregates $(>1 \mathrm{~mm})$ was increased, while that of small aggregates $(<1 \mathrm{~mm})$ was decreased during the overwinter time (Figure 5$)$. These results supported some previous studies suggesting that freezing-thawing cycles promoted the formation of large-size aggregates $[17,40]$. Two possible mechanisms might be responsible for the outcomes. First, for soils with high clay contents, the intra-aggregate pores are generally smaller than the inter-aggregate pores, and the ice "disjointing pressure" (which increased with the ratio of ice-filled pores) in inter-aggregates is higher than that in intra-aggregates. As a result, small aggregates are combined into large aggregates passively. Second, the double negative electric charges shell existing on the surfaces of clay particles can absorb large amounts of unfrozen water, which enhances the intermolecular forces among soil particles during the freezing process and promotes cementation and flocculation [41]. Hence, 
the rates of aggregation might be higher than that of fragmentation for soils with relatively higher clay contents $[37,42]$.

There was a lack of consistent trends in aggregate-size distribution between the two surface cover treatments, and between the two study years, except that the magnitude of changes in aggregate size distribution was less noticeable under moderate compaction. Further studies are required to understand the interactive effects of thermal processes, hydraulic processes, initial and boundary conditions on soil aggregation during freezing and thawing processes.

\section{Conclusions}

We have investigated the changes in total porosity, pore-size distribution, and aggregation of compacted soil layers in the 2016/2017 and 2017/3018 overwinter periods. An increase in total porosity and a greater portion of large pores were observed at all three compaction levels, under both bare and mulch surface conditions, and in both winters. The magnitude of these changes increased with the initial compaction level, and was greater in the mulch plot. The ice-filled pores space, which increased with the initial compacted level, was responsible for the variations in soil porosity and pore size distribution among different treatments. We also showed that following the overwinter freezing and thawing process, the ratio of large-size aggregates $(>1 \mathrm{~mm})$ was increased and the fraction of small-size aggregates $(<1 \mathrm{~mm})$ was decreased.

Our results demonstrate that the freezing-thawing process during overwinter time is an effective natural force for alleviating the negative effects of subsurface compaction in northeast China. It offers an alternative method to subsoiling tillage, which is labor- and time-intensive, and usually brings secondary compaction risks.

Author Contributions: L.W. conducted the experiment, collected the data, and drafted the article. H.W., Z.T., Y.L., W.G., and T.R. participated in design of the work, helped in data analysis and interpretation, and revised the manuscript. All authors have read and agreed to the published version of the manuscript.

Funding: This research was funded by the National Key Research and Development Program of China [2016YFD0300804-3] and the National Program on Key Basic Research Project [2015CB150403].

Conflicts of Interest: The authors declare that there is no conflict of interest regarding the publication of this article.

\section{References}

1. Bluett, C.; Tullberg, J.N.; McPhee, J.E.; Antille, D.L. Soil and tillage research: Why still focus on soil compaction? Soil Till. Res. 2019, 194, 104282. [CrossRef]

2. Jabro, J.D.; Iversen, W.M.; Evans, R.G.; Allen, B.L.; Stevens, W.B. Repeated freeze-thaw cycle effects on soil compaction in a clay loam in Northeastern Montana. Soil Sci. Soc. Am. J. 2014, 78, 737-744. [CrossRef]

3. Tracy, B.F.; Zhang, Y. Soil compaction, corn yield response, and soil nutrient pool dynamics within an integrated crop-livestock system in Illinois. Crop. Sci. 2008, 48, 1211-1218. [CrossRef]

4. Flowers, M.D.; Lal, R. Axle load and tillage effects on soil physical properties and soybean grain yield on a mollic ochraqualf in northwest Ohio. Soil Till. Res. 1998, 48, 21-35. [CrossRef]

5. Wolkowski, R.P. Relationship between Wheel-traffic-induced soil compaction, nutrient availability, and crop growth - a review. J. Prod. Agric. 1990, 3, 460-469. [CrossRef]

6. Lipiec, J.; Stepniewski, W. Effects of soil compaction and tillage systems on uptake and losses of nutrients. Soil Till. Res. 1995, 35, 37-52. [CrossRef]

7. Edwards, L.M.; Burney, J.R. The Effect of antecedent freeze-thaw frequency on runoff and soil loss from frozen soil with and without subsoil compaction and ground cover. Can. J. Soil Sci. 1989, 69, 799-811. [CrossRef]

8. Alaoui, A.; Rogger, M.; Peth, S.; Bloschl, G. Does soil compaction increase floods? A review. J. Hydrol. 2018, 557, 631-642. [CrossRef]

9. Keller, T.; Trautner, A.; Arvidsson, J. Stress distribution and soil displacement under a rubber-tracked and a wheeled tractor during ploughing, both on-land and within furrows. Soil Till. Res. 2002, 68, 39-47. [CrossRef] 
10. Saini, G.R. Soil Compaction and freezing and thawing. Soil Sci. Soc. Am. J. 1978, 42, 843-844. [CrossRef]

11. Valentine, T.A.; Hallett, P.D.; Binnie, K.; Young, M.W.; Squire, G.R.; Hawes, C.; Bengough, A.G. Soil strength and macropore volume limit root elongation rates in many UK agricultural soils. Ann. Bot.-Lond. 2012, 110, 259-270. [CrossRef] [PubMed]

12. Pagliai, M.; Vignozzi, N. The soil pore system as an indicator of soil quality. Adv. Geoecol. 2002, 35, 71-82.

13. Gradwell, M.W. Pore-size distributions of some new-zealand soil groups. N. Z. J. Agr. Res. 1978, $21,603-614$. [CrossRef]

14. Unger, P.W. Overwinter Changes in physical-properties of no-tillage soil. Soil Sci. Soc. Am. J. 1991, 55, 778-782. [CrossRef]

15. Deng, X.M.; Wang, J.; Zhu, W.S.; Chen, D.S.; Liu, L.P. Effects of frost action on soil physical properties of plough pan. Chin. Sci. Bull. 1999, 44, 445-448. [CrossRef]

16. Wang, E.H.; Cruse, R.M.; Chen, X.W.; Daigh, A. Effects of moisture condition and freeze/thaw cycles on surface soil aggregate size distribution and stability. Can. J. Soil Sci. 2012, 92, 529-536. [CrossRef]

17. Ma, Q.H.; Zhang, K.L.; Jabro, J.D.; Ren, L.; Liu, H.Y. Freeze-thaw cycles effects on soil physical properties under different degraded conditions in Northeast China. Environ. Earth Sci. 2019, 78, 321. [CrossRef]

18. Blake, G.R.; Nelson, W.W.; Allmaras, R.R. Persistence of subsoil compaction in a mollisol. Soil Sci. Soc. Am. J. 1976, 40, 943-948. [CrossRef]

19. Voorhees, W.B.; Senst, C.G.; Nelson, W.W. Compaction and soil structure modification by wheel traffic in Northern Corn Belt. Soil Sci. Soc. Am. J. 1978, 42, 344-349. [CrossRef]

20. Heinonen, R. Towards normal soil bulk-density. Soil Sci. Soc. Am. J. 1977, 41, 1214-1215. [CrossRef]

21. Chamberlain, E.J.; Gow, A.J. Effect of freezing and thawing on the permeability and structure of soils. Eng. Geol. 1979, 13, 73-92. [CrossRef]

22. Oztas, T.; Fayetorbay, F. Effect of freezing and thawing processes on soil aggregate stability. Catena 2003, 52, 1-8. [CrossRef]

23. Sahin, U.; Angin, I.; Kiziloglu, F.M. Effect of freezing and thawing processes on some physical properties of saline-sodic soils mixed with sewage sludge or fly ash. Soil Till. Res. 2008, 99, 254-260. [CrossRef]

24. Zhang, Z.L.; Cui, Z.D. Effects of freezing-thawing and cyclic loading on pore size distribution of silty clay by mercury intrusion porosimetry. Cold Reg. Sci. Technol. 2018, 145, 185-196. [CrossRef]

25. Zhang, X.Y.; Cruse, R.M.; Sui, Y.Y.; Jhao, Z. Soil compaction induced by small tractor traffic in northeast China. Soil Sci. Soc. Am. J. 2006, 70, 613-619. [CrossRef]

26. Wang, Q.J.; Lu, C.Y.; Li, H.W.; He, J.; Sarker, K.K.; Rasaily, R.G.; Liang, Z.H.; Qiao, X.D.; Hui, L.; Mchugh, A.D.J. The effects of no-tillage with subsoiling on soil properties and maize yield: 12-Year experiment on alkaline soils of Northeast China. Soil Till. Res. 2014, 137, 43-49. [CrossRef]

27. Van Genuchten, M.T. A Closed-form equation for predicting the hydraulic conductivity of unsaturated soils. Soil Sci. Soc. Am. J. 1980, 44, 892-898. [CrossRef]

28. Reynolds, W.D.; Drury, C.F.; Tan, C.S.; Fox, C.A.; Yang, X.M. Use of indicators and pore volume-function characteristics to quantify soil physical quality. Geoderma 2009, 152, 252-263. [CrossRef]

29. Dexter, A.R. Soil physical quality - Part I. Theory, effects of soil texture, density, and organic matter, and effects on root growth. Geoderma 2004, 120, 201-214. [CrossRef]

30. Deeks, L.K.; Bengough, A.G.; Low, D.; Billett, M.F.; Zhang, X.; Crawford, J.W.; Chessell, J.M.; Young, I.M. Spatial variation of effective porosity and its implications for discharge in an upland headwater catchment in Scotland. J. Hydrol. 2004, 290, 217-228. [CrossRef]

31. Radke, J.K.; Berry, E.C. Sore water and solute movement and bulk density changes in repacked soil columns as a result of freezing and thawing under field conditions. Soil. Sci. 1998, 163, 611-624. [CrossRef]

32. Viklander, P. Permeability and volume changes in till due to cyclic freeze/thaw. Can. Geotech. J. 1998, 35, 471-477. [CrossRef]

33. Walder, J.S.; Hallet, B. The physical basis of frost weathering-toward a more fundamental and unified perspective. Arct. Alp. Res. 1986, 18, 27-32. [CrossRef]

34. Style, R.W.; Peppin, S.S.L. The kinetics of ice-lens growth in porous media. J. Fluid Mech. 2012, 692, $482-498$. [CrossRef]

35. Hallet, B.; Walder, J.S.; Stubbs, C.W. Weathering by segregation ice growth in microcracks at sustained subzero temperatures: Verification from an experimental study using acoustic emissions. Permafr. Periglac. 1991, 2, 283-300. [CrossRef] 
36. Pawluk, S. Freeze-thaw effects on granular structure reorganization for soil materials of varying texture and moisture-content. Can. J. Soil Sci. 1988, 68, 485-494. [CrossRef]

37. Zhang, Z.; Ma, W.; Feng, W.J.; Xiao, D.H.; Hou, X. Reconstruction of soil particle composition during freeze-thaw cycling: a review. Pedosphere 2016, 26, 167-179. [CrossRef]

38. Bullock, M.S.; Kemper, W.D.; Nelson, S.D. Soil cohesion as affected by freezing, water-content, time and tillage. Soil Sci. Soc. Am. J. 1988, 52, 770-776. [CrossRef]

39. Nickling, W.G.; Bennett, L. The shear-strength characteristics of frozen coarse granular debris. J. Glaciol. 1984, 30, 348-357. [CrossRef]

40. Staricka, J.A.; Benoit, G.R. Freeze-drying effects on wet and dry soil aggregate stability. Soil Sci. Soc. Am. J. 1995, 59, 218-223. [CrossRef]

41. Perfect, E.; Vanloon, W.K.P.; Kay, B.D.; Groenevelt, P.H. Influence of ice segregation and solutes on soil structural stability. Can. J. Soil Sci. 1990, 70, 571-581. [CrossRef]

42. Horn, R.; Smucker, A. Structure formation and its consequences for gas and water transport in unsaturated arable and forest soils. Soil Till. Res. 2005, 82, 5-14. [CrossRef]

(C) 2020 by the authors. Licensee MDPI, Basel, Switzerland. This article is an open access article distributed under the terms and conditions of the Creative Commons Attribution (CC BY) license (http://creativecommons.org/licenses/by/4.0/). 